This item was submitted to Loughborough's Research Repository by the author.

Items in Figshare are protected by copyright, with all rights reserved, unless otherwise indicated.

\title{
The problem of a subjective authenticity and the articulation of belonging among the Irish in England-a psychosocial approach
}

\section{PLEASE CITE THE PUBLISHED VERSION}

http://dx.doi.org/10.1080/14780887.2014.958369

\section{PUBLISHER}

(C) Taylor \& Francis Group

\section{VERSION}

AM (Accepted Manuscript)

\section{PUBLISHER STATEMENT}

This work is made available according to the conditions of the Creative Commons Attribution-NonCommercialNoDerivatives 4.0 International (CC BY-NC-ND 4.0) licence. Full details of this licence are available at: https://creativecommons.org/licenses/by-nc-nd/4.0/

\section{LICENCE}

CC BY-NC-ND 4.0

\section{REPOSITORY RECORD}

Scully, Marc D.. 2019. "The Problem of a Subjective Authenticity and the Articulation of Belonging Among the Irish in England-a Psychosocial Approach". figshare. https://hdl.handle.net/2134/19563. 
The problem of a subjective 'authenticity' and the articulation of 'belonging' among the Irish in England - a psychosocial approach.

\author{
Marc Scully \\ University of Leicester
}

\begin{abstract}
This paper presents the question of identity and authenticity as a problematic one, capable of investigation through a psychosocial lens. 'Authenticity', as explored by Erickson (1995) and Weigert (1988, 2009) may be understood as a commitment to self-values, meaning and motivation. Feeling 'true to oneself' thus becomes an intensely personal affective project, which remains theoretically the preserve of the individual subject, and thus incapable of challenge by others. However, as identity is inherently social, there is a need to interrogate the affective nature of belonging to a collective identity. In particular, I consider how this personalised sense of authenticity may come into conflict with the need to have one's personal identity recognised as authentic within the wider set of meaning-makings around the collectivity. I argue that this problem of authenticity and belonging may arise in the interplay between the personal and the collective in three ways: reflection, recognition and ownership. Any articulation of belonging to a collective identity whilst maintaining a personally 'felt' authenticity must negotiate these three aspects. In this paper, I develop these ideas through my own recent research on discourses of authenticity among the Irish in England. Drawing on Wetherell's (2012) recent articulation of the affective-discursive I explore how one secondgeneration Irish woman articulates her experiences of 'belonging' and personal 'authenticity' in interview talk. I argue that the resolution of dilemmas around the affective and collective nature of authenticity can be usefully investigated by attending to the co-construction of the interview between participant and interviewer. The positioning of the interviewer and the power dynamics of the interview thus become key modes of enquiry in the psychosocial analysis of authenticity.
\end{abstract}

\title{
Introduction: Authenticity, affect and the psychosocial
}

In keeping with the theme of the special issue, this paper proposes the study of authenticity, and more particularly how 'authenticity' is negotiated by individuals in talk, as a useful worked example in researching the psychosocial. As a component of identity construction, authenticity is both inherently personal, in having a subjective emotional dimension, and inherently social, in being subject to broader normativities. Equally, these two dimensions are inextricably interrelated - the subjective dimension of 'feeling' authentic is shaped by social norms around potential identities, whereas authenticity as it is socially determined regularly appears to rest on some understanding of affect.

In order to explore authenticity as a topic for psychosocial research, I refer to my own work on authenticity and national identity among the Irish in England. This research set out to identify the discourses that shape what it means to be 'authentically' Irish in England, and how such discourses are drawn upon by individual Irish people in articulating their own identities. 
This paper will therefore first explore the intermingling of individual and social understandings of authenticity, illustrated by the example of the second generation Irish in England, and argue for a psychosocial approach to understanding the position of the subject within such processes. I will then discuss the suitability of the research interview as a means of exploring how individuals are positioned by discourses of authenticity, and the emphasis that analysis of such data should take. I provide a worked example from a research interview with Helen, a second-generation Irish woman who participated in my $\mathrm{PhD}$ research, and conclude by suggesting how the psychosocial study of authenticity might fit within the 'turn to affect', and particularly Wetherell’s (2012, 2013) articulation of an affective-discursive approach.

The advantage of a psychosocial approach to authenticity is that it enables enquiry after the affective dimension of subjective feelings of authenticity, and individual striving towards 'an authentic self' without assuming that a bounded, essential self is an entity that objectively exists. Similarly, this allows an analysis of the psychological consequences of collective identities being imagined as resting on some form of recognisable authenticity, while acknowledging this authenticity as a shared construct rather than an essentialist characteristic of a specific group. This interrelationship has been explored by Weigert, who argues:

As a dialectical social process unifying object and subject, self raises a conundrum: self is not a real object, yet strives for and is defined by others as more or less authentic (Weigert, 2009, p. 38).

Similarly, Rebecca Erickson argues that "being authentic in today's world does not necessarily mean that one is remaining true to some sort of unified or noncontradictory self” (Erickson, 1995, p. 135). Rather, she conceptualises authenticity as a commitment to self-values and argues that it can be explored through the process by which the subjective experience of feeling "true to oneself" is constructed and articulated. This does not imply that this experience is not infused with wider social meanings; something particularly true on those occasions where being 'true to oneself' involves identifying oneself as a member of a broader group and hence aligning oneself with a collective identity. Due to collective identities being socially constructed and shaped by structural forces and power relations, the agency of the individual in articulating feelings of being 'true to oneself' is constrained by societal meanings around what it means to be a member of a group. This, then, is the social rather than the subjective dimension of authenticity; rather than "feeling true to oneself"; authenticity here is composed of discourses around what the characteristics of a member of a group should be. Should the individual articulate a set of meanings around being a group member based on "feeling true to oneself" that are at odds with the prevailing set of social meanings around being a member of a group, then the individual is likely to be positioned as inauthentic. As Erickson argues, "members of oppressed groups are more likely to confront the 'problem' of authenticity than are those who inhabit the world of power and privilege" (Erickson, 1995, p. 137). It is useful to take a broad definition of 'oppressed' here. For example, Erickson illustrates the struggle faced by minority group members in articulating identities contrary to hegemonic, reified understandings through Shelby Steele's (1990, in Erickson 1995) discussion of how it felt to be both black and middle-class in the 1960s. Thus, as well as drawing on discourses of authenticity in order to construct an identity, individuals 
are also positioned by these same discourses, and the level of agency they possess to shape how they are positioned is determined by power relations.

With regard to the second-generation Irish in England, Hickman et al (2005) have argued that those of Irish descent in England are required to negotiate their identities within the intersection of the two hegemonic domains of Ireland and England. Under this formulation the 'England' domain is incorporating, denying the difference of Irishness, whereas the 'Ireland' domain is differentiating, denying of commonalities with people of Irish descent. (p.177) These domains are in turn inscribed with varying levels of power and privilege, with regard to the historical colonial relationship between Ireland and England, the position of the Irish in England as a 'suspect community' during the 1970s and 1980s, and class dynamics. The latter is arguably particularly pronounced: Mac an Ghaill \& Haywood (2003) have argued that discourses of class and modernity imbued the position of second-generation Irish migrants as 'inauthentic' by the 'elite workers' of the 1980s generation of Irish migration. The coining of the term 'Plastic Paddy' to denote this perceived inauthenticity reflects this.

I argue that the "problem of authenticity" may arise in the link between personal identity and collective identity in three ways: reflection, recognition and ownership. For a personal identity that is embedded in a collective identity to be 'felt' as authentic, the collective identity must in some way reflect the personal identity in order to permit identification between the personal and the collective. However, this collective identity must also be recognised as authentic within the broader discursive horizon of the construction of meaning. As suggested above, the latter is particularly salient for members of minority groups, whereby hegemonic stereotyped versions of the collective identity have affective and structural consequences for the individual.

This may in turn provoke debates over the ownership of such collective identities. Such rhetorical work again operates on two interrelated psychosocial levels, a personal identity that is 'mine', within a collective identity that is 'ours'. The composition of the imagined community of 'we', that are seen as having, and can claim ownership over the collective identity will have implications for the individual's ability to articulate ownership of his/her personal identity.

With regard to my own work on Irish authenticity, therefore, this refers to the articulation of a personal sense of Irishness as true to oneself, which is both situated in and reflected by a collective Irish identity that has achieved recognition as a 'true' representation of the Irish in England, who in turn have asserted ownership over the concept of Irishness. In other words, a personal Irishness that is 'mine' and "feels right” within a collective Irishness that is 'ours' and "looks right”.

An authentic personal Irish identity must be articulated in such a way that it does not contradict previous discursive work around other aspects of one's identity, but at the same time it must correspond with socially shared constructions of what an authentic Irish identity constitutes. On this point, I disagree with Erickson who has argued that authenticity is a self-referential concept that does not explicitly include any reference to 'others'. On the contrary, I agree with Weigert in arguing for a self-authenticity that is profoundly dialogical, and that constructions of an authentic collective identity will be rhetorically arranged around those who are positioned as inauthentic in relation to 
Irishness. Additionally, these socially shared constructions of authenticity are contextually bound. Analytically, the researcher may attend to the ways in which what counts as authentic and inauthentic is produced in the specific interactional context in which it is evoked and how this depends on the rhetorical work around Irish authenticity that the speaker is attending to.

\section{Methodology and context}

My approach to exploring the psychosocial dimension of authenticity draws on Wetherell's (2012) discussion of the affective-discursive which argues that 'affect' is not straightforwardly separable from the discursive activity surrounding the articulation and co-construction of the affective. In attempting to apply an affectivediscursive analytic framework, I am adopting an interpersonal understanding of 'affect' which largely focuses on the distributed, social nature of feeling and emotion. This is a necessarily narrow definition of the affective, which excludes some of the wider (and wilder) aspects of the 'turn to affect'. As outlined below, this approach to affect is predominantly data rather than theory-driven: I will discuss some of the wider questions of how a psychosocial approach to authenticity might relate to theories of affect later.

In order to explore how subjective feelings of authenticity are shaped by the broader discursive context of what is acknowledged as an authentic identity, I take the example of second-generation Irishness in England. Past research on the identity work carried out by those of Irish descent in England has highlighted the constraints placed upon the articulation of such identities by broader discourses of what it means to be Irish vis-à-vis what it means to be English (Hickman et al., 2005). In particular, second-generation narratives regularly feature accounts of having their Irish identities denigrated, or simply dismissed as inauthentic by those born in Ireland, either on family visits to Ireland, or by Irish migrants in England (Campbell, 1999; Free, 2007; Mac an Ghaill \& Haywood, 2003; Scully, 2009; Sorohan, 2012; Ullah, 1990). An individual second-generation person attempting to articulate his or her affective sense of Irishness must therefore negotiate their subject position within these wider discourses of national identity.

The analysis in this article is drawn from the transcript from a research interview carried out in 2008 as part of my doctoral studies. In particular, it represents an attempt to re-read, revisit and reinterpret the transcript, some years after my initial analysis, with a greater focus on the psychosocial dynamics of the interaction. While my initial analysis was largely concerned with identifying patterns across a corpus of data, in order to build broader discourses of authenticity, this analysis focuses on extracts from a single interview. Phoenix's (2008) focus on how 'key narratives' can be an analytical tool for examining the interrelationship of personal and canonical narratives was a key influence.

In looking at the psychosocial dynamics of this interaction, it is necessary to focus on the discursive and rhetorical strategies used both by the participant and by the interviewer. While it is now almost a truism within qualitative research that interviews are co-constructed between interviewer and participant, this can occasionally appear as something that merely needs to be briefly acknowledged, 
before proceeding with an analysis of the participant's responses, more or less in isolation. However, this is insufficient for a psychosocial approach to authenticity the extent to which authenticity rests on some level of social recognition, presupposes a dialogic element to 'feelings' of authenticity, which are shaped by wider social understandings of authentic identity. Within the interview scenario, articulations of authenticity, whether personal or collective, need to be constructed in such a way both to be recognisable to an imagined wider audience (who may or may not be explicitly referred to) and an immediately present audience in the person of the interviewer. As Phoenix (2008) puts it, interviewees make assumptions about interviewers that influence the claims they make about their own identities, and bring their histories of previous positioning and their expectations of the interviewer and the interview to the research context.

Attending to this dynamic is particularly important when both participants in the interview share, at least to some extent, a cultural identity relevant to the conversation, as highlighted by Song and Parker (1995) and De Andrade (2000). When speaking in terms of authenticity therefore, the interview becomes a dialogue whereby both interviewer and participant manage, and seek to assert their subjective sense of authenticity while co-constructing and acknowledging a collective authenticity within which they can both position themselves. However, as pointed out by Kvale (2006), power dynamics within the interview setting are not equal, with the interviewer having a monopoly on interpretation. It is also arguable that the nature of 'insider research' compounds the issue of power relations within the interview setting, particularly when (as outlined by De Andrade (2000)), interviewer and participant occupy different subject positions within the same 'imagined community'. This is complicated further when wider understandings of authenticity associated with a specific identity, means that one participant or the other has to do a greater amount of discursive work in order to have his/her subjective authenticity recognised.

In concrete terms, such dynamics are traceable in the interview extracts quoted below. As already outlined, the authenticity of second-generation Irish identities is frequently challenged, particularly by, and in comparison to those born in Ireland. It can be predicted therefore that for second generation migrants, encounters with those born in Ireland will be inscribed by previous similar encounters, as well as with an awareness of wider contestations of authenticity. Where the interview scenario is an example of such an encounter, it is likely that this will have an effect on the mutual positioning of interviewer and participant vis-à-vis 'authentic Irishness' as well as on the coconstruction of an authenticity recognisable to both participants in the exchange.

Interview participants may employ different discursive strategies when it comes to the negotiation of entitlement to speak about identity and authenticity. For example, Phoenix (2008) has outlined how a participant managed her 'troubled subject position' by establishing her personal credentials to speak authoritatively about racism. However, it seems likely that a 'troubled subject position' may be negotiated by conceding the rhetorical ground as much as by occupying it: in such cases, we might expect to see repeated instances of hedging and repair in the participants' speech, in order to avoid 'over-stretching' in their claim to a specific identity.

The following extracts are taken from my interview with Helen, one of the participants in my $\mathrm{PhD}$ research. Helen and I were both in our mid-twenties at the 
time of the interview, came from similar socio-economic backgrounds, and lived in the same area of southern England. Gender differences aside therefore (and it is not my intention to downplay the extent to which an interaction between interviewer and participant can be gendered), the most pertinent contrast between us in the context of the interview is our variable positioning with regard to Irishness. Whereas Helen was born in England, of two Irish parents, I was born in Ireland and had recently moved to England at the time. Thus, in the immediate context of the interaction, and in the knowledge that the subject of the interview was Irish identity, Helen may be described as occupying a 'troubled subject position' due to the constraints placed on the articulation of second generation identity as highlighted earlier.

The extracts are notable, and were partly selected due to the high instances of 'emotives' (i.e. direct declarative expressions of feeling therein). Whereas Wetherell's critique of Reddy's concept of emotives as over-simplistic in not capturing the complexity of discursive action (Wetherell, 2012, p. 71) is well-founded, there is still some value to the concept as a starting point for analysis. The use of a number of emotives within an interview extract is a strong indication of explicit discursive work around affect - while this is not to exclude subtler forms of signalling the affective, the use of emotives clearly signals the mutual discussion and understanding of a subjective state - precisely the stuff of psychosocial enquiry.

\section{Analysis}

The first extract ${ }^{1}$ specifically refers back to an earlier point in the conversation where Helen had described in detail her regular visits to the West of Ireland, and her descriptions of negotiating her Irish and British identities on such visits.

Marc: .hh erm going back to (.) I mean life over here even without reference to going back erm (.) are there (.) like times when you feel Irish and times that you feel British or do you kind of feel both simultaneously .hh

Helen: Ah erm (.) hmm that's interesting I think (.) there's definitely times when I feel more Irish or I feel more British [Marc: yeah] it's *more like * in a reverse when I'm in Ireland .hh (.) before I start speaking .hh and when I'm just on my own and reflecting on it, I feel more Irish because (.) I don't know I can just sort of see like the land my (.) my grandparents .hh had and things like that and [Marc: hmm] I just .hh sometimes I see myself in people like when you go to church and stuff .hh because there are distant cousins and things [Marc: hmm] erm but if I'm in a group of people .hh or hh or Irish people .hh I sometimes really feel like I don't fit in .hh [Marc: hmm] although I'm listening to them and I'm completely agreeing with what they're saying .hh I'm just keeping quiet and I'm thinking 'yeah I'm really thinking that too' .hh I'm too s-I don't know s-I think I might say something stupid .hh because as soon as I start speaking it's just I sound so British .hh and I hate my accent over there it's like (.) someone turns the volume up it's just like accentuated [Marc: hh] .hh and I think 'oh' (.) I just feel so awkward talking over there (.) but when I'm in England I suppose when people round me aren't Irish and they maybe have never been there [Marc: hmm] .hh you kind of feel like I've got something to say I can talk about (.) my experiences [Marc: hmm] *although I don't live there * I .hh I don't want to pretend I know all-everything about it coz I only know a little

\footnotetext{
${ }^{1}$ I use a modified version of Jeffersonian transcription where (.) indicates a short pause, hh indicates an out-breath, .hh indicates an in-breath etc. ${ }^{*} *$ signs around a segment of text indicates that the words were spoken in a 'laughing' voice.
} 
bit .hh but I know my parent's experiences [Marc: hmm] and (.) I kind of talk about that a bit (2) so

It is important to note that this stretch of conversation is framed from the beginning by me as the interviewer as one where discursive work around 'feeling' states is appropriate. However, Helen expands on my initial attempt to draw a contrast between 'feeling Irish' and 'feeling British' with a more considered, situated account of how her subjective feelings of Irishness and Britishness intersect with her physical and social environment. She emphasizes the greater affective potential for identification when 'on her own and reflecting on it', something she associates with her grandparents land and 'seeing herself' in local people in Ireland. She then draws a contrast between 'seeing' and 'speaking', describing the embarrassment she associates with speaking in her English accent in an Irish milieu in quite intensely affective language - "I hate my accent over there", "I just feel so awkward talking over there". (This corresponds with what Walter (2008) has noted about the centrality of accent to an 'authentic' Irishness, and the corresponding positioning of second-generation people with English accents as inauthentic).

From a psychosocial perspective, this is a fascinating picture of the ways in which subjective and social meanings of authenticity intersect. Helen creates a narrative where a subjective authentic Irishness is possible, but only where this can be kept separate from larger social meanings of Irishness, where these are embodied by other Irish people. The constraints placed on her feelings of 'authentically' belonging by broader discourses linking nationality with accent, prevent her from feeling able to participate in conversations marked as 'Irish', and quite literally leave her voiceless.

That this constraint is situational is made obvious by Helen then outlining scenarios in England where she describes herself as feeling 'she has something to say' about Irishness, although she quickly qualifies this by emphasizing that she is not claiming 'to know everything about it'. This may qualify as a moment of repair, in the sense that it is used by Wetherell $(1998)$ and similarly by Taylor $(2005,2006)$ in relation to 'troubled identities' that are potentially challengeable by a real or imagined interlocutor. Given that Helen has just spoken of her discomfort in speaking about her Irishness with other Irish people, the fact that the interview scenario is precisely this may have influenced her qualification of her knowledge claims. It is possible that the same dynamic is in effect in the following excerpt, slightly later in the conversation, when I return to the topic of the interpersonal constraints of Helen's feelings of Irishness:

Marc: (2) er say if you were (.) kind of (.) if you met an Irish person over here [Helen: hmm] (.) would you bring it up (.) straight away?

Helen: Erm .hh it might sound strange I think I'd probably just quickly .hh just to say it but (.) I wouldn't want to talk about it too much because I don't want to annoy anybody [Marc: right] I know it might sound silly but I think .hh if it was me and I'd think oh God the last thing I'd want is somebody .hh preaching to *me about how Irish they are* or saying .hh all this stuff and it's be-I don't know I just don't want to em- .hh embarrass me or embarrass them [Marc: hmm] .hh because at the end of the day (.) they live in Ireland, they've grown up there .hh sometimes *I feel .hh I don't know that much* you know my parents (.) were born they grew up there .hh but I was br-br-brought up in England so I [Marc: yeah] wouldn't want to 
profess to be *some kind of expert on things* .

The effect of this conversation appears to place Helen outside the category of 'Irish person'. My initial framing of the question could be read as leaving the question of who constitutes 'an Irish person over here' open to include those of Irish descent however, Helen clearly interprets this as a far more bounded category to denote those born and raised in Ireland. Again, it is probably relevant here that Helen's reluctance to claim Irishness in an imagined conversation with someone born and brought up in Ireland occurs in the context of an actual conversation with someone born and brought up in Ireland: one might speculate how the nature of the conversation would have altered if the initial question was posed by a second-generation Irish person. Helen's unwillingness to claim Irishness due to an expressed lack of knowledge of lived experience of Irishness (I have written about the hegemonic nature of this discourse of transnational knowledge elsewhere - see Scully (2012)) is also framed in affective terms - she speaks of a reluctance to speak at length about her own Irishness due to the fear of causing annoyance or embarrassment. Again, from a psychosocial perspective, this reluctance to claim a social category, being justified by an appeal to psychological states is interesting.

Referring back to my initial discussion of how 'authenticity' operates in identity work, the importance of an identity position 'feeling right' when making a link between personal and collective identities is illustrated by Helen's negotiation of her own Irishness, and her reluctance to claim anything other than a highly subjective and situational identification with Irishness. This negotiation is also shaped by Irishness 'looking right' - however, despite my earlier distinction between 'feeling right' and 'looking right', it seems clear from the following extract that there is also an affective dimension to representation.

Helen: I mean .hh (.) in my first year at Uni there were Irish people on my course and .hh and also in our halls of residence but .hh I never really (.) got to know them that well [Marc: yeah] .hh not because I didn't like them or anything but .hh I mean one example was (.) there was like an Irish S-society set up (.) [Marc: hmm] my friends were like 'you should join, you should join it' and I thought .hh 'okay I'll sort of put my name down' (.) but I was really kind of, almost slightly intimidated because (.) .hh you get emails and (.) they would kind of have the stereotypical (.) phrases in it and stuff [Marc: yeah] and I just .hh that really just put me off and I just thought I just don't want to be a part of *this* .hh so erm

Marc: I-is this going back to the subtlety thing again?

Helen: [Yeah] I think so I just get embarrassed when people (.) really shove it in your face a bit [Marc: yeah] I-I'm proud of it in (.) different ways about you know the cultural side of it not the sort of the really kind of materialistic things that they promote in shops and things [Marc: yeah] I just th-I just don't want people (.) having that sort .hh stereotypical view [Marc: yeah] of it something I just-I wouldn't play up to it [Marc: hmm] so erm .hh it puts me off when people say things like s-certain phrases or .hh or you know pictures-I mean it's-it's fun and like [Marc: yeah] you can (.) .hh *it's going to make me sound really bitter * [Marc: snigger] .hh because I can take a joke and everything but I don't (.) I want uspeople to see through (.) all of that sort of commercial side of it.

Marc: Yeah (.) when you say commercial side of it now what kind of thing do you have in mind?

Helen: Erm just like this (.) the stereotypical images or the stories or the .hh erm the 
way that sometimes they portray it (.) on television or characters and things like that

[Marc: yeah] or

Marc: Kind of er dancing [leprechauns is it]

Helen: [Yeah] that's it and the things-

Marc: and top of the morning to you

Helen: Exactly [Marc: yeah] and it just .hh just (.) I mean I (.) it's probably just me coz I-I don't know .hh i-if people who live in Ireland prob-they might embrace that I don't know [Marc: yeah] to be honest (.) and good on them, you know, fair enough (.) I just don't want-I just want people to think-know that there's more to that [Marc: yeah, yeah] than just that (laughs)

Within her narrative of joining her university Irish society, Helen again outlines the extent to which her subjective identification with Irishness is 'troubled' by wider social understandings of what Irishness constitutes. Here however, the issue is less that Helen is constructing her Irish identity as not being recognised as such, but rather that she does not recognise the representation of Irishness associated with the Irish society as accurately reflecting her own subjective take on Irish authenticity. Once again, this moment of disidentification is characterised in affective terms - Helen description of herself as being 'almost slightly intimidated' by the society is interesting, particularly when taken in conjunction with her previous wishes to avoid social situations in which Irishness is collectively constructed.

Given that this is a qualitatively different form of Helen expressing discomfort around inauthenticity, what starts to emerge here is a kind of hierarchy of authenticity, whereby Helen positions herself as not having the requisite knowledge to claim authentic Irishness on the same level as those born in Ireland, but nevertheless positions herself as having a more authentic affective relationship with Irishness than the superficial markers employed by the Irish Society. I then begin to co-construct a picture of what 'inauthentic' stereotypical markers of Irishness might look like by offering a few suggestions which Helen adopts. However, Helen then again appears to perform some discursive repair in hesitantly allowing for the possibility that such markers may be adopted by 'people who live in Ireland', who again are positioned as having more legitimate ownership of Irishness. At the same time, this exists alongside a wish that an imagined audience (presumably of non-Irish people) would not identify stereotypical Irishness with the 'more cultural side of it' that she identifies with. Thus, there is a multiple problem of recognition, reflection and authenticity here, with Helen not recognising the 'commercial' Irishness as reflecting her own affective identification, while also expressing a wish that Irishness as a collective identity would be recognised as multi-faceted. Taken together, this creates something of an ideological dilemma, which is only partly resolved by stressing that this is a purely personal wish.

\section{Discussion \& Conclusion}

Helen is not presented here as any kind of exemplar of second-generation Irishness, nor should the way that she negotiates authenticity within this context be seen as in any way typical. However, taking a psychosocial perspective allows us to analytically situate Helen's identity work within the wider context of the constraints placed on second-generation Irishness, thus highlighting the inextricably interwoven nature of the psychological and the social, as well as allowing for a more in-depth analysis of the affective dimension of authenticity within identity discourse. 
In speaking of this affective dimension of authenticity, I have already noted that I am working with a relatively narrow conception of 'affect', concentrating on the distributed, social nature of feeling and emotion. I do not argue that this is all 'affect' constitutes, but rather that this may be considered a subset of affective practice. However, it may be that my analytic lens in revisiting this interview has been too narrow to adequately capture the kinds of affective practice underway here. In particular, I am sympathetic to arguments that the embodied nature of encounters are an integral part of the affective e.g. (Clough, 2010), and that efforts to study it must in some way orient towards this. This is obviously difficult to achieve when revisiting a transcript that was originally taken from an audio recording of a relatively standard research interview. Ideally therefore, from the point of view of the analyst, some means of tracing how bodies, as well as voices, create discourse, may be preferable.

However, incomplete though a methodology of revisiting transcripts may be for tracing the affective nature of an encounter, I would argue that there is more to the above extract than simply Helen talking about 'how it feels' to be second-generation Irish. Wetherell has argued that "a central part of affective practices consists of accounts and narratives of affect, past, present and future. In learning how to perform affect in socially recognisable and conventional ways, people also learn how to talk about and evaluate affect" (2012, p. 93). That the above interview is a form of affective practice is highlighted by moments where Helen draws attention to the fact that her narrative of occasions where she has felt uncomfortable regarding the 'authenticity' of her Irish identity is in itself, a self-conscious performance of affect: she pauses to qualify her accounts with phrases such as "it might sound strange", "I know it might sound silly", "it's going to make me sound really bitter". Thus, there is an affective strand here that runs through these encounters: how Helen felt at the time, how Helen felt she was perceived at the time, how Helen felt during the interview, and how Helen felt she was perceived by me during the interview. Therefore, Helen's discursive work in these short sentences does not just account for 'feeling', but encompasses a range of different situated affective practices.

A psychosocial approach to authenticity, therefore, in stressing that authenticity is inextricably both personal and social, similarly emphasises that 'feeling true to oneself' is not just an experience of subjective emotion, but also a situated affective practice. As such enquiring after authenticity as the subjective state of feeling true to oneself is inextricably bound up with how such feelings are made sense of discursively, and are performed in affective practice. This is not merely a matter of it being only methodologically possible to analyse subjective feelings once they have been 'translated' into discourse, but rather as argued above, that there is a dialogic and distributed dimension to affect, that is given shape within a specific interaction by the discursive.

This worked example has also served to highlight how the respective subject positions adopted by (and ascribed to) interviewer and participant add a layer of complexity to the negotiation of identities and the articulation of affective stances. In particular, from my own perspective, it has been an instructive example of the worth of revisiting interview data with a different analytical focus. As argued by Andrews (2008), as analysts our conclusions are always provisional, and subject to reinterpretation in the light of personal, historic and changes, as well as developments in the nature of the 
discipline. An increasing interest in the psychosocial may be seen as one such change, and while this may well inspire new methodologies to address new research questions, there is also a great deal of potential in using the psychosocial as a retrospective lens to re-evaluate previous work.

Andrews, M. (2008). Never the last word: Revisiting data. In M. Andrews, C. Squire \& M. Tamboukou (Eds.), Doing Narrative Research (pp. 86-101). London: Sage.

Campbell, S. (1999). Beyond 'Plastic Paddy': A Re-examination of the SecondGeneration Irish in England. Immigrants and Minorities, 18(2/3), 266-288.

Clough, P. T. (2010). The Affective Turn: Political Economy, Biomedia and Bodies. In M. Gregg \& G. J. Seigworth (Eds.), The Affect Theory Reader (pp. 206225). London: Duke University Press.

De Andrade, L. L. (2000). Negotiating from the Inside: Constructing Racial and Ethnic Identity in Qualitative Research. Journal of Contemporary Ethnography, 29(3), 268-290.

Erickson, R. J. (1995). The Importance of Authenticity for Self and Society. Symbolic Interaction, 18(2), 121-144.

Free, M. (2007). Tales from the Fifth Green Field: The Psychodynamics of Migration, Masculinity and National Identity amongst Republic of Ireland Soccer Supporters in England. Sport in Society, 10(3), 476-494.

Hickman, M. J., Morgan, S., Walter, B., \& Bradley, J. (2005). The Limitations of Whiteness and the Boundaries of Englishness. Ethnicities, 5(2), 160-182.

Kvale, S. (2006). Dominance Through Interviews and Dialogues. Qualitative Inquiry, $12,480-500$.

Mac an Ghaill, M., \& Haywood, C. (2003). Young (male) Irelanders: postcolonial ethnicities - expanding the nation and Irishness. European Journal of Cultural Studies, 6, 386-403.

Phoenix, A. (2008). Analysing narrative contexts. In M. Andrews, C. Squire \& M. Tamboukou (Eds.), Doing Narrative Research (pp. 64-77). London: Sage.

Scully, M. (2009). 'Plastic and Proud'? Discourses of Authenticity among the SecondGeneration Irish in England. Psychology \& Society, 2(2), 124-135.

Scully, M. (2012). The tyranny of transnational discourse: 'authenticity' and Irish diasporic identity in Ireland and England. Nations and Nationalism, 18(2), 191-209.

Song, M., \& Parker, D. (1995). Commonality, Difference and the Dynamics of Disclosure in In-Depth Interviewing. Sociology, 29(2), 241-256.

Sorohan, S. (2012). Irish London During the Troubles. Dublin: Irish Academic Press.

Taylor, S. (2005). Self-narration as rehearsal: A discursive approach to the narrative formation of identity. Narrative Inquiry, 15(1), 45-50.

Taylor, S. (2006). Narrative as construction and discursive resource. Narrative Inquiry, 16(1), 94-102.

Ullah, P. (1990). Rhetoric and ideology in social identification: the case of second generation Irish youths. . Discourse \& Society, 1(2), 167-188.

Walter, B. (2008). Voices in other ears: "accents" and identities of the first- and second-generation Irish in England. In G. Rings \& A. Ife (Eds.), Neo-colonial 
mentalities in contemporary Europe?: Language and discourse in the construction of identities (pp. 174-182). Cambridge: Cambridge Scholars Publishing.

Weigert, A. J. (2009). Self Authenticity as Master Motive. In P. Vannini \& J. P. Williams (Eds.), Authenticity in Culture, Self and Society (pp. 37-50). Farnham: Ashgate.

Wetherell, M. (1998). Positioning and interpretative repertoires: conversation analysis and post-structuralism in dialogue. Discourse and Society, 9(3), 387-412.

Wetherell, M. (2012). Affect and Emotion: A New Social Science Understanding. London: Sage.

Wetherell, M. (2013). Affect and discourse - What's the problem? From affect as excess to affective/discursive practice. Subjectivity, 6(4), 349-368. 